\title{
Ex vivo peripheral blood mononuclear cell response to R848 in children after supplementation with the probiotic Lactobacillus acidophilus NCFM/Bifidobacterium
}

\section{lactis $\mathrm{Bi}-07$}

\author{
G.P. DeMuri ${ }^{1 *}$, L.M. Lehtoranta ${ }^{2}$, J.C. Eickhoff ${ }^{1}$, M.J. Lehtinen ${ }^{2}$ and E.R. Wald ${ }^{1}$ \\ ${ }^{1}$ Department of Pediatrics, University of Wisconsin-Madison School of Medicine and Public Health, 600 Highland Avenue, \\ Madison, WI 53972, USA; ${ }^{2}$ DuPont Nutrition and Biosciences, Danisco Sweeteners Oy, Sokeritehtaantie 20, Kantvik 02460, \\ Finland; demuri@pediatrics.wisc.edu
}

Received: 10 April 2020 / Accepted: 7 November 2020

(c) 2021 Wageningen Academic Publishers

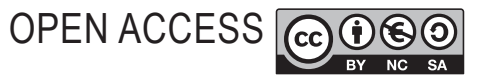

RESEARCH ARTICLE

\begin{abstract}
Several studies have demonstrated a decrease in upper respiratory infection (URI) frequency and severity in subjects taking probiotic supplements. We hypothesised beneficial effects of probiotics on viral URI in children are due to modulation of inflammatory innate immune responses. We tested this hypothesis, providing children with a probiotic combination of Lactobacillus acidophilus/Bidfidobacterium animalis ssp. lactis Bi-07 (NCFM/Bi-07) and measuring levels of cytokines in response to stimulation of peripheral blood mononuclear cells (PBMCs) to toll-like receptor (TLR) 7/8 agonist resiquimod (R848). In this open label study, 21 (2 dropouts) children received probiotic containing $5 \times 10^{9} \mathrm{cfu}$ each of NCFM/(Bi-07) daily for 30 days. Whole blood was taken from each subject at study entry and 30 days for culture of PBMCs. PBMCs stimulated with resiquimod (R848) or unstimulated were incubated and a panel of immune markers was measured. There was a significant decrease in the net (stimulated-null) level of myeloid progenitor inhibitory factor 1 (MPIF-1) (mean decrease $0.1 \mathrm{ng} / \mathrm{ml}, 95 \%$ confidence interval 0.01-0.24, $P=0.032$ ) following probiotic supplementation. The change in immune marker levels after supplementation, when analysed together with respect to expected inflammatory/anti-inflammatory effects, was increased for interleukin (IL)-10 and decreased for MPIF-1, IL-8, interferon gamma induced protein 10, macrophage inflammatory protein 3 alpha (MIP-3 $\alpha)$ and E-selectin ( $P=0.01)$. Adverse events were mild. In conclusion, supplementation with this probiotic combination was safe and resulted in significant modulation of PBMC limited immune response to TLR7/8 agonist R848 and in levels of MPIF-1 and MIP-3 $\alpha$. The anti-inflammatory effect may be one mechanism by which probiotics modulate the immune system however further study is needed.
\end{abstract}

Keywords: probiotic, upper respiratory infection, Lactobacillus, Bifidobacterium

\section{Introduction}

The acute upper respiratory infection (URI) is the most frequent infection experienced by children and adults. URI is frequently complicated by bacterial infections, such as acute otitis media, acute sinusitis or pneumonia, especially in children. Concern from practitioners for 'missing' important bacterial complications of URI leads to inappropriate antibiotic use and contributes to the local and global problems of antibiotic resistance. In addition, viral URI may be the most important trigger for acute episodes of wheezing and exacerbations of reactive airways disease and asthma (Olenec et al., 2010). The population of the US experiences approximately 500 million URIs per year with an economic impact of $\$ 40$ billion annually including a loss of an estimated 22 million school days and 20 million work days (Fendrick et al., 2003). Despite such a high prevalence, serious health consequences and huge economic burden there are very few preventative or treatment options for URI. 
There has been considerable interest in the use of probiotics to reduce the risk of URI and/or to shorten the duration of symptoms across all age groups. Several studies investigating various probiotics particularly in children have shown a decrease in the number of URIs (Hatakka et al., 2001; Hojsak et al., 2010; Lin et al., 2009; Luoto et al., 2014; Maldonado et al., 2012; Merenstein et al., 2010; Taipale et al., 2011) and a reduction in duration and severity of symptoms (Giovannini et al., 2007; Hatakka et al., 2001; Hojsak et al., 2010; Kukkonen et al., 2008; Kumpu et al., 2012; Leyer et al., 2009; Rautava et al., 2009; Rerksuppaphol and Rerksuppaphol, 2012; Sazawal et al., 2010; Weizman et al., 2005). In particular, a randomised, double-blind, controlled study (Gerasimov et al., 2016) showed that Lactobacillus acidophilus DDS-1 and Bifidobacterium lactis UABLA-12 shortened the duration of URI in children and a review of probiotics in children attending day care centres concluded that Lactobaccillus rhamnosus GG had a modest effect on reducing the duration of URIs (Laursen and Hojsak, 2018). Additionally, meta-analyses including both children and adults (King et al., 2014) or focusing only on children (Wang et al., 2016) have shown that probiotic consumption leads to shorter duration of illness, fewer illness episodes, as well as fewer days of absence from day care/school. Although meta-analyses and multiple studies show efficacy of probiotics in general, several individual studies have found no impact of probiotics on URI in children. The current scientific consensus is that the effects of probiotics on immunomodulation are strain specific (Hill et al., 2014). This underscores the need to understand the mechanisms of this phenomenon and the effect of strain or strain combinations on immune responses and clinical benefits.

The effects of a probiotic combination L. acidophilus NCFM (NCFM) and Bifidobacterium animalis spp. lactis Bi-07 (Bi-07) on URI has been investigated in clinical trials in children and in adults (Fisberg et al., 2002; Leyer et al., 2009; West et al., 2014a,b). Leyer et al. (2009) evaluated the effect of NCFM and a combination of NCFM and Bi-07 (NCFM/Bi-07) on URI in healthy children 3 to 6 years of age in a double-blind, randomised, placebo-controlled clinical trial. Children who received NCFM/Bi07 had a reduction of fever, cough and rhinorrhoea, and shorter duration of symptoms, as well as reduced antibiotic use and days absent from group child care and work (for parents) compared to those who received placebo (Leyer et al., 2009). In another clinical trial, a subgroup of 3- to 5-year old underweight children consuming NCFM/Bi-07 together with fructooligosaccharide in a nutritional supplement had fewer gastrointestinal and respiratory illness associated sick days compared with those receiving the nutritional supplement alone (Fisberg et al., 2002). On the other hand, in a clinical study conducted in an active healthy adult population the efficacy of NCFM/Bi-07 on URI was more subtle than in children and NCFM/Bi-07 had no effect on peripheral blood immune markers, reflecting potential differences in the immune system between children and adults (Cox et al., 2014; West et al., 2014a).

The development of the immune system throughout childhood is dynamic and dependent on the influence of gut microbiota and nutrition (Kollmann et al., 2012). Therefore, probiotics with immunomodulatory properties may have a more pronounced impact on children than adults. However, there is limited evidence on how probiotics influence the immune system of children and whether alterations in the function of the immune system by the probiotic may account for the decrease in frequency and severity of viral URIs. We hypothesised that the beneficial effects of probiotics on viral URI in children are at least partly due to modulation of the inflammatory innate immune response which constitutes the initial host response to viral infection. We tested this hypothesis in a clinical trial by providing children with a combination of probiotics NCFM and Bi-07 for one month and then measuring the levels of cytokines/chemokines in response to stimulation of whole blood derived PBMCs to the toll like receptor 7/8 agonist resiquimod (R848) - a mimic of a viral infection.

\section{Materials and methods}

This study was an, open label clinical trial approved by the Institutional Review Board of the University of WisconsinMadison (approval date January 04, 2017). All procedures performed were in accordance with International Conference on Harmonization of Good Clinical Practice guidelines and in agreement with the Declaration of Helsinki (World Medical Association 2013) and registered in Clinicaltrials.gov with identifier NCT02687503.

Healthy children, 13 to 36 months of age, were recruited from two paediatric primary care practices in Madison, WI, USA. A study nurse obtained written informed consent from the parents or legal representatives of the child before initiating study procedures. Children were excluded from this study if they had any of the following: asthma/ allergic rhinitis, premature birth (<36 weeks gestation), immunodeficiency or any underlying problem requiring the use of steroids or other immunosuppressive agents, the use of nonsteroidal anti-inflammatory drugs in the last 2 weeks, any antibiotic treatment in the last 3 months, and conditions which might interfere with dispersion of the probiotic after oral administration, such as anomalies of the digestive tract. Also excluded were children who were currently receiving probiotics, having received probiotics in the previous two weeks or unwilling to refrain from the use of probiotics during the three months prior to study entry. In addition, children concurrently participating in another clinical study, were excluded from this study. 
Children received a probiotic product consisting of $5 \times 10^{9}$ cfu of $L$. acidophilus NCFM and $5 \times 10^{9} \mathrm{cfu}$ of $B$. animalis ssp. lactis $\mathrm{Bi}-07$ in $1 \mathrm{~g}$ of sucrose as a carrier (HOWARU ${ }^{\circ}$ Protect Kids, manufactured by DuPont, Madison WI, USA) given once a day orally in milk or juice for 30 days. The probiotic product was provided by the manufacturer in sachets which were dispensed by a central pharmacy and stored under refrigeration by the caregivers until used. Compliance with the study product was assessed from a diary completed by the parents/caregivers over the course of the study.

\section{Sample analysis}

Whole blood samples were taken from each subject at study entry (pre-supplementation) and 30 days after starting probiotic (post-supplementation) for culture of peripheral blood mononuclear cells (PBMCs) using the TruCulture ${ }^{\circ}$ (RBM Myriad, Austin, TX, USA) system. PBMCs stimulated with R848 at a final concentration of $1 \mu \mathrm{M}$ and unstimulated (null) were incubated for 24 hours at $37^{\circ} \mathrm{C}$. A detailed description of these procedures is found elsewhere (Duffy et al., 2014).

For determination of cytokine levels, samples were transported on dry ice to a commercial laboratory (Myriad RBM) and analysed for expression of cytokines and chemokines using a proprietary Luminex Bead technology and assay platform (Human CytokineMAP A v.1.0) which included E-selectin, interferon gamma induced protein (IP10), chemokine (C-X-C motif) ligand 10 (CXCL10)), tumour necrosis factor alpha (TNF- $\alpha$ ), tumour necrosis factor beta (TNF- $\beta$ ), interleukin(IL)-6 receptor (IL-6r), macrophage inflammatory protein 3 alpha (MIP-3 $\alpha$ ), chemokine (C-C motif) ligand 20 (CCL20)), monokine induced by gamma interferon (MIG, CXCL9), myeloid progenitor inhibitory factor 1 (MPIF-1, CCL23), granulocyte-macrophage colonystimulating factor (GM-CSF), interferon gamma (IFN- $\gamma$ ), IL-2, IL-3, IL-4, IL-5, IL-6, IL-7, IL-8 (CXCL8), IL-10, IL-18, macrophage inflammatory protein-1 alpha (MIP-1 $\alpha$, CCL3), macrophage inflammatory protein-1 beta (MIP-1 $\beta$ CCL4), and monocyte chemotactic protein 1 (MCP-1, CCL2).

\section{Adverse effects}

Potential adverse events were monitored on a weekly basis during the 30-day study period including fever, diarrhoea, loose stools, frequent stools, rash, abdominal pain/colic, constipation, diaper rash, other illness, and physician visits.

\section{Statistics}

As this was an exploratory study, a pre-determined statistical analysis plan was not applied. Changes in net cytokine/chemokine levels (R484 stimulated minus null value) from the pre- to the post-probiotic assessment were evaluated using a paired t-test. Values were log-transformed before conducting the comparisons to satisfy the normality assumption. Absolute differences in net cytokine/ chemokine levels were summarised in terms of means and $95 \%$ confidence intervals (CI). All reported $P$-values are two-sided and $P<0.05$ was used to define statistical significance level. Due to the exploratory nature of the study, no false discovery adjustments were used when comparing changes in individual cytokine/chemokine levels.

As an additional exploratory analysis, the null hypothesis that net cytokine level following one month of probiotic supplementation does not result in a change in the panel of IL-10, IL-8, IP-10, MIP-3 $\alpha$, MPIF-1 and E-selectin values was tested against the alternative that it does result in an anticipated increase in IL-10 levels combined with an anticipated decrease in IL-8, IP-10, MIP-3 $\alpha$, MPIF1, E-selectin marker levels (anti-inflammatory effect). A chi-square test of expected (under the null hypothesis) vs observed direction of changes in the cytokine/chemokine panel was then conducted to test whether net (R848 stimulated-null) PBMCs following one month of probiotic supplementation results in an anticipated increase in IL-10 levels combined with an anticipated decrease in IL-8, IP-10, MIP-3 $\alpha$, MPIF-1, E-selectin marker levels.

Statistical analyses were conducted using SAS software (SAS Institute Inc., Cary, NC, USA).

\section{Results}

\section{Subjects}

Twenty-three subjects were enrolled in the study over a six-month period. Two subjects were withdrawn as blood was not able to be obtained at the initial visit (presupplementation). Two additional subjects had successful venipuncture at the initial visit but blood was unable to be obtained at the second visit. Thus, a total of 21 presupplementation and 19 post-supplementation samples were used in the final analysis (Figure 1). The mean age of subjects was 19.9 months (range 12-36 months). Subjects identified as White, non-Hispanic (90\%), Asian (5\%), and Black (5\%); $43 \%$ were female.

\section{Immune marker analysis}

The results of stimulated immune marker measurements are shown in Table 1. Taken individually, there was a significant decrease in net (R848 stimulated-null) measurements of MPIF- $1(-0.1 \mathrm{ng} / \mathrm{ml}, 95 \%$ CI: $-0.2--0.01 \mathrm{ng} / \mathrm{ml}, P=0.032)$ in whole blood following 30 days of probiotic supplementation. Furthermore, a marginal decrease in MIP- $3 \alpha(-385.9 \mathrm{pg} /$ $\mathrm{ml}, 95 \% \mathrm{CI}:-779.7-7.1 \mathrm{pg} / \mathrm{ml}, P=0.05)$ was observed after probiotic supplementation. There was a trend for an increase in IL-10 $(P=0.1)$. 


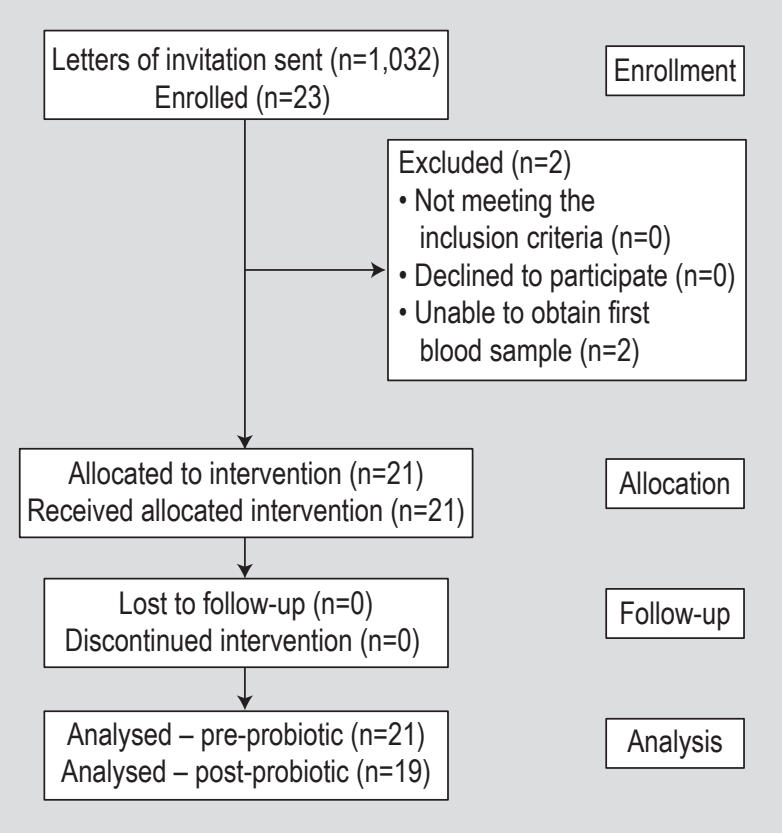

Figure 1. CONSORT 2010 flow diagram.
The distribution of immune marker levels is shown in boxwhisker plots in Figure 2. The change in immune marker levels, post-probiotic supplementation, when analysed together with respect to expected pro-inflammatory/antiinflammatory effects, was significantly increased for IL-10 and significantly decreased for MPIF-1, IL-8, IP-10, MIP-3 $\alpha$ and E-selectin $(P=0.01)$.

\section{Safety and adherence}

Table 2 shows reported potential adverse events during the 30-day study. All adverse events were considered mild and no subject discontinued probiotic. In addition, a causal relationship between the events noted and probiotic was not established. One patient had a medically attended visit for rash not attributable to probiotic. No serious adverse events were observed. The adherence to the study product was as follows: no missed doses were reported in 13 subjects, 6 subjects reported a single missed dose and 1 subject each reported two and three missed doses.

Table 1. Mean net (R848 stimulated-null) cytokine/chemokine whole blood levels before and after 30-day probiotic intake.

\begin{tabular}{|c|c|c|c|c|c|}
\hline Analyte $^{1}$ & Unit & Pre-probiotic (Mean) & Post-probiotic (Mean) & Mean change $(95 \% \mathrm{Cl})$ & $P$-value ${ }^{2}$ \\
\hline E-selectin & $\mathrm{ng} / \mathrm{ml}$ & 0.4 & 0.7 & $0.2(-0.9-1.3)$ & 0.69 \\
\hline GM-CSF & $\mathrm{pg} / \mathrm{ml}$ & 12.9 & 11.3 & $-3.0(-10.7-4.7)$ & 0.43 \\
\hline IFN-y & $\mathrm{pg} / \mathrm{ml}$ & 473.2 & 491.6 & $-7.2(-176.1-161.5)$ & 0.92 \\
\hline IL-2 & $\mathrm{pg} / \mathrm{ml}$ & $0.0^{3}$ & $0.0^{3}$ & 0 & NS \\
\hline IL-3 & $\mathrm{ng} / \mathrm{ml}$ & 0.0 & 0.0 & 0 & NS \\
\hline IL-4 & $\mathrm{pg} / \mathrm{ml}$ & 4.4 & 0 & $-4.8(-10.4-0.8)$ & 0.09 \\
\hline IL-5 & $\mathrm{pg} / \mathrm{ml}$ & $0.0^{3}$ & $0.0^{3}$ & 0 & NS \\
\hline IL-6 & $\mathrm{pg} / \mathrm{ml}$ & $18,641.8$ & $16,355.1$ & $-2,670.2(-9,194.7-3,854.2)$ & 0.40 \\
\hline IL-6r & $\mathrm{ng} / \mathrm{ml}$ & 1.2 & 0.7 & $-0.4(-2.6-1.9)$ & 0.73 \\
\hline IL-7 & $\mathrm{pg} / \mathrm{ml}$ & 25.1 & 22.0 & $-1.9(-18.7-14.9)$ & 0.82 \\
\hline IL-8 & $\mathrm{pg} / \mathrm{ml}$ & $7,077.4$ & $5,056.9$ & $-2,003.2(-4,438.3-432)$ & 0.10 \\
\hline IL-10 & $\mathrm{pg} / \mathrm{ml}$ & $2,687.2$ & $3,110.9$ & $501.1(-104.6-1,106.8)$ & 0.10 \\
\hline IL-18 & $\mathrm{pg} / \mathrm{ml}$ & 49.6 & 58.6 & $-15.9(-34.7-66.5)$ & 0.52 \\
\hline IP-10 & $\mathrm{pg} / \mathrm{ml}$ & $37,700.1$ & $30,491.9$ & $-5,863.0(-14,182-2,456.2)$ & 0.16 \\
\hline MCP-1 & $\mathrm{pg} / \mathrm{ml}$ & $46,732.8$ & $48,499.4$ & $3,076.4(-6,104.6-12,257.4)$ & 0.49 \\
\hline MCP-2 & $\mathrm{pg} / \mathrm{ml}$ & $1,5618.8$ & $15,456.5$ & $113.4(-3,163.6-3,390.4)$ & 0.94 \\
\hline MIG & $\mathrm{pg} / \mathrm{ml}$ & $2,467.9$ & $2,024.3$ & $-392.8(-879.5-93.8)$ & 0.11 \\
\hline MIP-1a & $\mathrm{pg} / \mathrm{ml}$ & $43,030.7$ & $44,897.6$ & $1,030.3(-10,973.5-13,034.2)$ & 0.86 \\
\hline MIP-1 $1 \beta$ & $\mathrm{pg} / \mathrm{ml}$ & $851,420.7$ & $852,574.7$ & $-6,348.3(-201,413.9-188,717.4)$ & 0.95 \\
\hline MIP-3a & $\mathrm{pg} / \mathrm{ml}$ & $1,908.2$ & $1,497.2$ & $-385.9(-779.7-7.1)$ & 0.053 \\
\hline MPIF-1 & $\mathrm{ng} / \mathrm{ml}$ & 0.3 & 0.2 & $-0.1(-0.2-0.0)$ & 0.03 \\
\hline TNF-a & $\mathrm{pg} / \mathrm{ml}$ & $22,565.7$ & $21,810.6$ & $-975.8(-6,434-4,482.4)$ & 0.71 \\
\hline TNF- $\beta$ & $\mathrm{pg} / \mathrm{ml}$ & 3.5 & 6.6 & $2.7(-6-11.3)$ & 0.52 \\
\hline
\end{tabular}

${ }^{1}$ GM-CSF = granulocyte-macrophage colony-stimulating factor; IFN = interferon; IL = interleukin; IP = interferon -induced protein; MCP = monocyte chemotactic protein; MIG = monokine induced by gamma interferon; MIP = macrophage inflammatory protein; MPIF = myeloid progenitor inhibitory factor; TNF = tumour necrosis factor.

${ }^{2} P$-value for evaluating change from between pre- and post-probiotic supplementation. NS = not significant.

${ }^{3}$ Lower detection limit. 

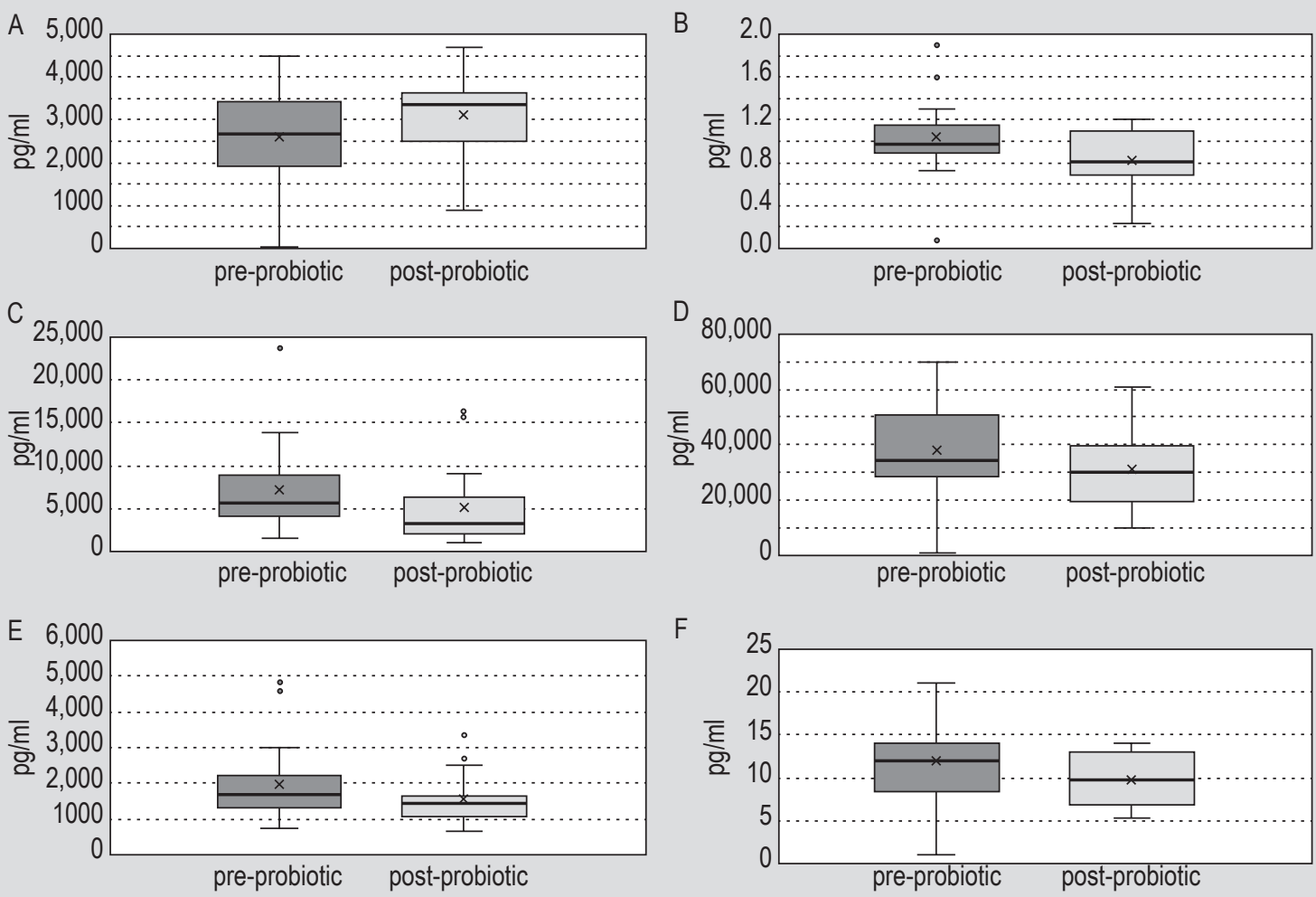

Figure 2. Box-whisker plots of (A) interleukin (IL)-10, (B) myeloid progenitor inhibitory factor 1, (C) IL-8, (D) interferon Y-induced protein 10, (E) macrophage inflammatory protein-3 $\alpha$ and $(F)$ E-selectin from peripheral blood mononuclear cells after stimulation with R848 pre-supplementation and post-supplementation with Lactobacillus acidophilus NCFM and Bifidobacterium lactis Bi-07. Cross represents the mean value.

Table 2. Adverse events during 30-day study period in 21 children.

$\begin{array}{llr}\text { Symptom } & \text { Number of subjects } & \% \\ \text { Diarrhoea } & 9 & 42.9 \\ \text { Constipation } & 7 & 33.3 \\ \text { Vomiting } & 0 & 0.0 \\ \text { Nausea } & 0 & 0.0 \\ \text { Gassy } & 4 & 19.0 \\ \text { Abdominal pain } & 1 & 4.8 \\ \text { Fussiness } & 7 & 33.3 \\ \text { Rash } & 4 & 19.0\end{array}$

\section{Discussion and conclusions}

We have demonstrated that daily supplementation with NCFM and Bi-07 has a limited but significant effect on peripheral blood innate immune function in response to TLR 7/8 agonist in children 13-36 months of age. After one month of supplementation, PBMC responses were significantly decreased for the cytokine MPIF-1 when stimulated with R848. When the immune markers were statistically analysed by categorising them as pro- or antiinflammatory, the impact of probiotic on R848 stimulated PBMCs was to exert an anti-inflammatory effect; namely an increase in IL-10 combined with a decrease in MPIF-1, MIP-3 $\alpha$, IL-8, IP-10 and E-selectin.

Toll-like receptors (TLRs) are a class of highly conserved pattern recognition receptors that are responsible for the initiation of the innate immune response by sensing molecular patterns for early recognition of a pathogen such as bacteria, viruses and protozoa. (Wallet et al., 2018). The natural ligands for TLR 7/8 are single stranded RNA molecules such as those found in viruses which are potent stimulators of the innate immune response (Gaajetaan $e t$ al., 2012; Vasilakos and Tomai, 2013). In addition, TLR7 recognises rhinovirus and has been demonstrated to govern the inflammatory response to rhinovirus infections (Hatchwell et al., 2015). TLR7 and TLR 8 are also involved in the recognition and response to other viral upper and lower respiratory infections including respiratory syncytial virus and influenza (Lukacs et al., 2010; Scagnolari et al., 2009; Stegemann-Koniszewski et al., 2018; Wu et al., 2013). We chose a stimulant, R848, that is a ligand of TLR 7/8 to model the inflammatory response to viral infection and determine the effect of probiotic supplementation on this 
innate response. Our results suggest that one mechanism of the effect of NCFM and Bi-07 and potentially other probiotics on viral URI may be to modulate the TLR7/8 induced inflammatory cascade and innate immune response to viruses.

Our study provides a possible mechanistic explanation for the reduction in respiratory symptoms experienced by children with URI who receive supplementation with probiotic. Levels of IL-8 and IP-10 correlate closely with symptoms during URI (Gern et al., 2002; Hayney et al., 2017). Thus, the reduction in IL-8 and IP-10 following supplementation with probiotic may be the mechanism of reduction of symptoms seen in the study by Leyer et al. (2009). The role of E-selectin in URI has not been described though it is a potent recruiter of neutrophils to sites of inflammation and infection (Silva et al., 2017). Our study suggests that NCFM/Bi07 may alter inflammation by decreasing expression of E-selectin. Turner et al. (2017) performed a study with another probiotic, B. lactis Bl-04, in experimental rhinovirus infection in human volunteers. In the probiotic group, higher levels of IL-8 in nasal lavage prior to virus challenge were observed. However, the baseline adjusted IL-8 response to rhinovirus infection in nasal lavage was significantly reduced in the probiotic group (Turner et al., 2017). Although this study was in adults and used different methods (nasal lavage) it tends to lend support to our finding that probiotics may influence cytokine and chemokine levels associated with an initial innate immune response. Although the probiotics in our study and the clinical studies mentioned were administered orally, the effect on respiratory immune function may occur due to dissemination from the gastrointestinal immune effector cells via the so-called gut-lung axis (Brandtzaeg, 2009; Dumas et al., 2018).

In contrast to the limited immunomodulatory effects that were observed in the present study in children, the effect of NCFM/Bi-07 supplementation on immune markers in adults has been less clear. West et al. (2014a,b, 2016) conducted a randomised, double-blind, placebo-controlled clinical study in healthy active adults and showed a delayed time to experiencing a first URI episode during the 'cold' season, but without effect on risk or duration of the symptoms with intake of NCFM/Bi-07. The different results observed between the present study in children and in the adult population may potentially reflect the differences in assaying the immune markers - challenged ex vivo PBMC cells vs plasma immune markers - or perhaps the developing immune system of children may be more prone to effects of probiotics.

A novel finding in our study was a significant reduction (in stimulated PBMCs) in levels of MPIF-1 and a decrease in MIP-3 after supplementation with NCFM/Bi-07. MPIF-1 is known to selectively recruit resting $\mathrm{T}$-lymphocytes and monocytes, inhibit proliferation of myeloid progenitor cells and promote angiogenesis. MIP-3 $\alpha$ is produced by human neutrophils and monocytes in response to R848 stimulation (Arruda-Silva et al., 2017). MIP-3 $\alpha$ is responsible for the chemoattraction of immature dendritic cells (DC), effector/ memory T-cells and B-cells and plays a role in inflammation in skin and mucosal surfaces. In an animal model of rotavirus infection, Zhou et al. (2019) demonstrated that neonatal rhesus monkeys showed elevated blood levels of the chemokines MPIF-1and MIP-3 $\alpha$ after infection with human rotaviruses suggesting they play an important role in the inflammatory response. A recent meta-analysis showed that probiotics exert a positive effect in reducing the duration of acute rotavirus diarrhoea compared with controls (Ahmadi et al., 2015). The effect of NCFM/Bi07 on these two chemokines may explain, in part, the mechanism by which probiotics moderate the symptoms of acute infectious diarrhoea from rotavirus.

The results of the present study showed that supplementation with a combination of NCFM and Bi-07 resulted in immunomodulatory effects towards a more anti-inflammatory response upon stimulation of PBMCs with R848 ex vivo. The direct effect of the combination of NCFM/Bi07 has not been investigated on PBMCs or immune cells in vitro, however, NCFM and $\mathrm{Bi}-07$ have been investigated separately suggesting that they upregulate key inflammatory pathways for innate viral defence (Foligne $e t$ al., 2007; Gad et al., 2011; Konstantinov et al., 2008; Weiss et al., 2010a,b).

Our study did not demonstrate differences in some cytokines that are known to play a role in the inflammatory response following viral URI. Most notably, IL-6 levels have been associated with URI and correlate with symptom severity; these were not changed in our study (Alper et al., 2010; Patel et al., 2009). However, our sample size was small and we assayed whole blood which may not reflect the environment in the nasal mucosa. In addition, we used only one stimulant of PBMCs (R848) and focused on a TLR 7/8 response which may have limited the scope of our findings. In addition, some cytokines such as interferon gamma are limited in utility as a biomarker during URI (Turner et al., 2017). Since other studies have failed to demonstrate an antiviral effect of a probiotic we did not assess levels of type I interferons in this study. It is difficult to assess the clinical significance of the immunomodulation as our study did not assess symptoms of URI. Further randomised doubleblind placebo-controlled trials with larger numbers are required to verify the findings of this study and to connect immunomodulation to health benefits in children.

Overall, the probiotic product was well-tolerated by study subjects, similar to other studies (Cox et al., 2014; Fisberg et al., 2002; Leyer et al., 2009; Schrezenmeir et al., 2004; West et al., 2014b). Potential adverse events were mild and 
no serious adverse events were noted. Adherence to the study product, as measured by parent/caregiver report, was excellent.

In conclusion, we have demonstrated that the supplementation with the probiotic combination $L$. acidophilus NCFM and B. lactis $\mathrm{Bi}-07$ resulted in modulation of the immune response to TLR7/8 agonist R848 and in levels of MPIF- 1 and marginally for MIP-3 $\alpha$. This effect may provide a mechanism by which probiotics ameliorate symptoms in viral upper respiratory and gastrointestinal infections but further studies are needed to investigate this effect.

\section{References}

Ahmadi, E., Alizadeh-Navaei, R. and Rezai, M.S., 2015. Efficacy of probiotic use in acute rotavirus diarrhea in children: A systematic review and meta-analysis. Caspian Journal of Internal Medicine 6: 187-195.

Alper, C.M., Li-Korotky, H.S., Lo, C.Y., Doyle, A.P., Winther, B. and Doyle, W.J., 2010. Nasal secretion concentrations of IL-5, IL-6, and IL-10 in children with and without upper respiratory tract viruses. Archives of Otolaryngology - Head and Neck Surgery 136: 281-286. https://doi.org/10.1001/archoto.2010.14

Arruda-Silva, F., Bianchetto-Aguilera, F., Gasperini, S., Polletti, S., Cosentino, E., Tamassia, N. and Cassatella, M.A., 2017. Human neutrophils produce CCL23 in response to various TLR-agonists and TNFalpha. Frontiers in Cellular and Infection Microbiology 7: 176. https://doi.org/10.3389/fcimb.2017.00176

Brandtzaeg, P., 2009. Mucosal immunity: induction, dissemination, and effector functions. Scandinavian Journal of Immunology 70: 505-515. https://doi.org/10.1111/j.1365-3083.2009.02319.x

Cox, A.J., West, N.P., Horn, P.L., Lehtinen, M.J., Koerbin, G., Pyne, D.B., Lahtinen, S.J., Fricker, P.A. and Cripps, A.W., 2014. Effects of probiotic supplementation over 5 months on routine haematology and clinical chemistry measures in healthy active adults. European Journal of Clinical Nutrition 68: 1255-1257. https://doi.org/10.1038/ ejcn.2014.137

Duffy, D., Rouilly, V., Libri, V., Hasan, M., Beitz, B., David, M., Urrutia, A., Bisiaux, A., Labrie, S.T., Dubois, A., Boneca, I.G., Delval, C., Thomas, S., Rogge, L., Schmolz, M., Quintana-Murci, L., Albert, M.L. and Milieu Interieur, C., 2014. Functional analysis via standardized whole-blood stimulation systems defines the boundaries of a healthy immune response to complex stimuli. Immunity 40: 436-450. https:// doi.org/10.1016/j.immuni.2014.03.002

Dumas, A., Bernard, L., Poquet, Y., Lugo-Villarino, G. and Neyrolles, O., 2018. The role of the lung microbiota and the gut-lung axis in respiratory infectious diseases. Cell Microbiology 20: e12966. https://doi.org/10.1111/cmi.12966

Fendrick, A.M., Monto, A.S., Nightengale, B. and Sarnes, M., 2003. The economic burden of non-influenza-related viral respiratory tract infection in the United States. Archives in Internal Medicine 163: 487-494.
Fisberg, M., Maulen-Radovan, I., Tormo, R., Taberono Carrascoso, M., Pedron Giner, C., Obasi, C.N., Argüelles Martin, F., Pavón Belinchón, P., Martínez-Costa, C., Perez, M., Gonzalez Caro, J., Vasquez-garibay, E., Alberto García Aranda, J., Maria Alfonso Pó, I., Villagómez Martínez, S., McCue, M., A. Alarcón, P. and M. Comer, G., 2002. Effect of oral nutritional supplementation with or without synbiotics on sickness and catch-up growth in preschool children. International Pediatrics 17: 216-222.

Foligne, B., Nutten, S., Grangette, C., Dennin, V., Goudercourt, D., Poiret, S., Dewulf, J., Brassart, D., Mercenier, A. and Pot, B., 2007. Correlation between in vitro and in vivo immunomodulatory properties of lactic acid bacteria. World Journal of Gastroenterology 13: 236-243. https://doi.org/10.3748/wjg.v13.i2.236

Gaajetaan, G.R., Bruggeman, C.A. and Stassen, F.R., 2012. The type I interferon response during viral infections: a 'SWOT' analysis. Reviews in Medical Virology 22: 122-137. https://doi.org/10.1002/ rmv.713

Gad, M., Ravn, P., Soborg, D.A., Lund-Jensen, K., Ouwehand, A.C. and Jensen, S.S., 2011. Regulation of the IL-10/IL-12 axis in human dendritic cells with probiotic bacteria. FEMS Immunology and Medical Microbiology 63: 93-107. https://doi.org/10.1111/j.1574695X.2011.00835.x

Gerasimov, S.V., Ivantsiv, V.A., Bobryk, L.M., Tsitsura, O.O., Dedyshin, L.P., Guta, N.V. and Yandyo, B.V., 2016. Role of short-term use of L. acidophilus DDS-1 and B. lactis UABLA-12 in acute respiratory infections in children: a randomized controlled trial. European Journal of Clinical Nutrition 70: 463-469. https://doi.org/10.1038/ ejcn.2015.171

Gern, J.E., Martin, M.S., Anklam, K.A., Shen, K., Roberg, K.A., Carlson-Dakes, K.T., Adler, K., Gilbertson-White, S., Hamilton, R., Shult, P.A., Kirk, C.J., Da Silva, D.F., Sund, S.A., Kosorok, M.R. and Lemanske, R.F., Jr., 2002. Relationships among specific viral pathogens, virus-induced interleukin-8, and respiratory symptoms in infancy. Pediatric Allergy and Immunology 13: 386-393.

Giovannini, M., Agostoni, C., Riva, E., Salvini, F., Ruscitto, A., Zuccotti, G.V. and Radaelli, G., 2007. A randomized prospective double blind controlled trial on effects of long-term consumption of fermented milk containing Lactobacillus casei in pre-school children with allergic asthma and/or rhinitis. Pediatric Research 62: 215-220. https://doi.org/10.1203/PDR.0b013e3180a76d94

Hatakka, K., Savilahti, E., Ponka, A., Meurman, J.H., Poussa, T., Nase, L., Saxelin, M. and Korpela, R., 2001. Effect of long-term consumption of probiotic milk on infections in children attending day care centres: double blind, randomised trial. BMJ 322: 1327.

Hatchwell, L., Collison, A., Girkin, J., Parsons, K., Li, J.Y., Zhang, J., Phipps, S., Knight, D., Bartlett, N.W., Johnston, S.L., Foster, P.S., Wark, P.A.B. and Mattes, J., 2015. Toll-like receptor 7 governs interferon and inflammatory responses to rhinovirus and is suppressed by IL-5-induced lung eosinophilia. Thorax 70: 854861. https://doi.org/10.1136/thoraxjnl-2014-205465

Hayney, M.S., Henriquez, K.M., Barnet, J.H., Ewers, T., Champion, H.M., Flannery, S. and Barrett, B., 2017. Serum IFN-gamma-induced protein 10 (IP-10) as a biomarker for severity of acute respiratory infection in healthy adults. Journal of Clinical Virology 90: 32-37. https://doi.org/10.1016/j.jcv.2017.03.003 
Hill, C., Guarner, F., Reid, G., Gibson, G.R., Merenstein, D.J., Pot, B., Morelli, L., Canani, R.B., Flint, H.J., Salminen, S., Calder, P.C. and Sanders, M.E., 2014. Expert consensus document. The International Scientific Association for Probiotics and Prebiotics consensus statement on the scope and appropriate use of the term probiotic. Nature Reviews Gastroenterology and Hepatology 11: 506-514. https://doi.org/10.1038/nrgastro.2014.66

Hojsak, I., Abdovic, S., Szajewska, H., Milosevic, M., Krznaric, Z. and Kolacek, S., 2010. Lactobacillus GG in the prevention of nosocomial gastrointestinal and respiratory tract infections. Pediatrics 125: e1171-1177. https://doi.org/10.1542/peds.2009-2568

King, S., Glanville, J., Sanders, M.E., Fitzgerald, A. and Varley, D., 2014. Effectiveness of probiotics on the duration of illness in healthy children and adults who develop common acute respiratory infectious conditions: a systematic review and meta-analysis. British Journal of Nutrition 112: 41-54. https://doi.org/10.1017/ S0007114514000075

Kollmann, T.R., Levy, O., Montgomery, R.R. and Goriely, S., 2012. Innate immune function by Toll-like receptors: distinct responses in newborns and the elderly. Immunity 37: 771-783. https://doi. org/10.1016/j.immuni.2012.10.014

Konstantinov, S.R., Smidt, H., de Vos, W.M., Bruijns, S.C., Singh, S.K., Valence, F., Molle, D., Lortal, S., Altermann, E., Klaenhammer, T.R. and van Kooyk, Y., 2008. S layer protein A of Lactobacillus acidophilus NCFM regulates immature dendritic cell and T cell functions. Proceedings of the National Academy of Sciences of the USA 105: 19474-19479. https://doi.org/10.1073/pnas.0810305105

Kukkonen, K., Savilahti, E., Haahtela, T., Juntunen-Backman, K., Korpela, R., Poussa, T., Tuure, T. and Kuitunen, M., 2008. Longterm safety and impact on infection rates of postnatal probiotic and prebiotic (synbiotic) treatment: randomized, double-blind, placebocontrolled trial. Pediatrics 122: 8-12. https://doi.org/10.1542/ peds.2007-1192

Kumpu, M., Kekkonen, R.A., Kautiainen, H., Jarvenpaa, S., Kristo, A., Huovinen, P., Pitkaranta, A., Korpela, R. and Hatakka, K., 2012. Milk containing probiotic Lactobacillus rhamnosus GG and respiratory illness in children: a randomized, double-blind, placebo-controlled trial. Eur J Clin Nutr 66: 1020-1023. https:// doi.org/10.1038/ejcn.2012.62

Laursen, R.P. and Hojsak, I., 2018. Probiotics for respiratory tract infections in children attending day care centers-a systematic review. European Journal of Pediatrics 177: 979-994. https://doi. org/10.1007/s00431-018-3167-1

Leyer, G.J., Li, S., Mubasher, M.E., Reifer, C. and Ouwehand, A.C., 2009. Probiotic effects on cold and influenza-like symptom incidence and duration in children. Pediatrics 124: e172-179. https://doi. org/10.1542/peds.2008-2666

Lin, J.S., Chiu, Y.H., Lin, N.T., Chu, C.H., Huang, K.C., Liao, K.W. and Peng, K.C., 2009. Different effects of probiotic species/strains on infections in preschool children: a double-blind, randomized, controlled study. Vaccine 27: 1073-1079. https://doi.org/10.1016/j. vaccine.2008.11.114
Lukacs, N.W., Smit, J.J., Mukherjee, S., Morris, S.B., Nunez, G. and Lindell, D.M., 2010. Respiratory virus-induced TLR7 activation controls IL-17-associated increased mucus via IL-23 regulation. Journal of Immunology 185: 2231-2239. https://doi.org/10.4049/ jimmunol.1000733

Luoto, R., Ruuskanen, O., Waris, M., Kalliomaki, M., Salminen, S. and Isolauri, E., 2014. Prebiotic and probiotic supplementation prevents rhinovirus infections in preterm infants: a randomized, placebocontrolled trial. Journal of Allergy and Clinical Immunology 133: 405-413. https://doi.org/10.1016/j.jaci.2013.08.020

Maldonado, J., Canabate, F., Sempere, L., Vela, F., Sanchez, A.R., Narbona, E., Lopez-Huertas, E., Geerlings, A., Valero, A.D., Olivares, M. and Lara-Villoslada, F., 2012. Human milk probiotic Lactobacillus fermentum CECT5716 reduces the incidence of gastrointestinal and upper respiratory tract infections in infants. Journal of Pediatric Gastroenterology and Nutrition 54: 55-61. https://doi.org/10.1097/ MPG.0b013e3182333f18

Merenstein, D., Murphy, M., Fokar, A., Hernandez, R.K., Park, H., Nsouli, H., Sanders, M.E., Davis, B.A., Niborski, V., Tondu, F. and Shara, N.M., 2010. Use of a fermented dairy probiotic drink containing Lactobacillus casei (DN-114 001) to decrease the rate of illness in kids: the DRINK study. A patient-oriented, double-blind, cluster-randomized, placebo-controlled, clinical trial. European Journal of Clinical Nutrition 64: 669-677. https://doi.org/10.1038/ ejcn.2010.65

Olenec, J.P., Kim, W.K., Lee, W.M., Vang, F., Pappas, T.E., Salazar, L.E., Evans, M.D., Bork, J., Roberg, K., Lemanske, R.F., Jr. and Gern, J.E., 2010. Weekly monitoring of children with asthma for infections and illness during common cold seasons. Journal of Allergy and Clinical Immunology 125: 1001-1006.e1001. https:// doi.org/10.1016/j.jaci.2010.01.059

Patel, J.A., Nair, S., Revai, K., Grady, J. and Chonmaitree, T., 2009. Nasopharyngeal acute phase cytokines in viral upper respiratory infection: impact on acute otitis media in children. Pediatric Infectious Disease Journal 28: 1002-1007. https://doi.org/10.1097/ INF.0b013e3181aa5b13

Rautava, S., Salminen, S. and Isolauri, E., 2009. Specific probiotics in reducing the risk of acute infections in infancy - a randomised, double-blind, placebo-controlled study. British Journal of Nutrition 101: 1722-1726. https://doi.org/10.1017/s0007114508116282

Rerksuppaphol, S. and Rerksuppaphol, L., 2012. Randomized controlled trial of probiotics to reduce common cold in schoolchildren. Pediatrics International 54: 682-687. https://doi.org/10.1111/j.1442200X.2012.03647.x

Sazawal, S., Dhingra, U., Hiremath, G., Sarkar, A., Dhingra, P., Dutta, A., Verma, P., Menon, V.P. and Black, R.E., 2010. Prebiotic and probiotic fortified milk in prevention of morbidities among children: community-based, randomized, double-blind, controlled trial. PLoS ONE 5: e12164. https://doi.org/10.1371/journal.pone.0012164

Scagnolari, C., Midulla, F., Pierangeli, A., Moretti, C., Bonci, E., Berardi, R., De Angelis, D., Selvaggi, C., Di Marco, P., Girardi, E. and Antonelli, G., 2009. Gene expression of nucleic acid-sensing pattern recognition receptors in children hospitalized for respiratory syncytial virus-associated acute bronchiolitis. Clinical and Vaccine Immunology 16: 816-823. https://doi.org/10.1128/CVI.00445-08 
Schrezenmeir, J., Heller, K., McCue, M., Llamas, C., Lam, W., Burow, H., Kindling-Rohracker, M., Fischer, W., Sengespeik, H.C., Comer, G.M. and Alarcon, P., 2004. Benefits of oral supplementation with and without synbiotics in young children with acute bacterial infections. Clinical Pediatrics 43: 239-249. https://doi. org/10.1177/000992280404300305

Silva, M., Videira, P.A. and Sackstein, R., 2017. E-selectin ligands in the human mononuclear phagocyte system: implications for infection, inflammation, and immunotherapy. Frontiers in Immunology 8: 1878. https://doi.org/10.3389/fimmu.2017.01878

Stegemann-Koniszewski, S., Behrens, S., Boehme, J.D., Hochnadel, I., Riese, P., Guzman, C.A., Kroger, A., Schreiber, J., Gunzer, M. and Bruder, D., 2018. Respiratory influenza a virus infection triggers local and systemic natural killer cell activation via toll-like receptor 7. Frontiers in Immunology 9: 245. https://doi.org/10.3389/ fimmu.2018.00245

Taipale, T., Pienihakkinen, K., Isolauri, E., Larsen, C., Brockmann, E., Alanen, P., Jokela, J. and Soderling, E., 2011. Bifidobacterium animalis subsp. lactis BB-12 in reducing the risk of infections in infancy. British Journal of Nutrition 105: 409-416. https://doi. org/10.1017/s0007114510003685

Turner, R.B., Woodfolk, J.A., Borish, L., Steinke, J.W., Patrie, J.T., Muehling, L.M., Lahtinen, S. and Lehtinen, M.J., 2017. Effect of probiotic on innate inflammatory response and viral shedding in experimental rhinovirus infection - a randomised controlled trial. Beneficial Microbes 8: 207-215. https://doi.org/10.3920/ BM2016.0160

Vasilakos, J.P. and Tomai, M.A., 2013. The use of Toll-like receptor 7/8 agonists as vaccine adjuvants. Expert Review of Vaccines 12: 809-819. https://doi.org/10.1586/14760584.2013.811208

Wallet, S.M., Puri, V. and Gibson, F.C., 2018. Linkage of infection to adverse systemic complications: periodontal disease, toll-like receptors, and other pattern recognition systems. Vaccines 6. https:// doi.org/10.3390/vaccines6020021

Wang, Y., Li, X., Ge, T., Xiao, Y., Liao, Y., Cui, Y., Zhang, Y., Ho, W., Yu, G. and Zhang, T., 2016. Probiotics for prevention and treatment of respiratory tract infections in children: a systematic review and meta-analysis of randomized controlled trials. Medicine 95: e4509. https://doi.org/10.1097/md.0000000000004509
Weiss, G., Rasmussen, S., Nielsen Fink, L., Jarmer, H., Nohr Nielsen, B. and Frokiaer, H., 2010a. Bifidobacterium bifidum actively changes the gene expression profile induced by Lactobacillus acidophilus in murine dendritic cells. PLoS ONE 5: e11065. https://doi. org/10.1371/journal.pone.0011065

Weiss, G., Rasmussen, S., Zeuthen, L.H., Nielsen, B.N., Jarmer, H., Jespersen, L. and Frokiaer, H., 2010b. Lactobacillus acidophilus induces virus immune defence genes in murine dendritic cells by a Toll-like receptor-2-dependent mechanism. Immunology 131: 268-281. https://doi.org/10.1111/j.1365-2567.2010.03301.x

Weizman, Z., Asli, G. and Alsheikh, A., 2005. Effect of a probiotic infant formula on infections in child care centers: comparison of two probiotic agents. Pediatrics 115: 5-9. https://doi.org/10.1542/ peds.2004-1815

West, N., Horn, P., Barrett, S., S. Warren, H., J. Lehtinen, M., Koerbin, G., Brun, M., Pyne, D., J. Lahtinen, S., A. Fricker, P. and Cripps, A., 2014a. Supplementation with a single and double strain probiotic on the innate immune system for respiratory illness. e-SPEN Journal 9. https://doi.org/10.1016/j.clnme.2014.06.003

West, N.P., Horn, P.L., Pyne, D.B., Gebski, V.J., Lahtinen, S.J., Fricker, P.A. and Cripps, A.W., 2014b. Probiotic supplementation for respiratory and gastrointestinal illness symptoms in healthy physically active individuals. Clinical Nutrition 33: 581-587. https:// doi.org/10.1016/j.clnu.2013.10.002

West, N.P., Horn, P.L., Pyne, D.B., Warren, H.S., Asad, S., Cox, A.J., Lahtinen, S.J., Lehtinen, M.J., Fricker, P.A., Cripps, A.W. and Fazekas de St Groth, B., 2016. Probiotic supplementation has little effect on peripheral blood regulatory T cells. Journal of Allergy and Clinical Immunology 138: 1749-1752. https://doi.org/10.1016/j. jaci.2016.06.055

Wu, S., Jiang, Z.Y., Sun, Y.F., Yu, B., Chen, J., Dai, C.Q., Wu, X.L., Tang, X.L. and Chen, X.Y., 2013. Microbiota regulates the TLR7 signaling pathway against respiratory tract influenza A virus infection. Current Microbiology 67: 414-422. https://doi.org/10.1007/s00284013-0380-z

Zhou, Y., Qiao, H., Yin, N., Chen, L., Xie, Y., Wu, J., Du, J., Lin, X., Wang, Y., Liu, Y., Yi, S., Zhang, G., Sun, M., He, Z. and Li, H., 2019. Immune and cytokine/chemokine responses of PBMCs in rotavirus-infected rhesus infants and their significance in viral pathogenesis. Journal of Medical Virology 91: 1448-1469. https:// doi.org/10.1002/jmv.25460 
